\title{
Research into the Effect of Supercapacitor Terminal Voltage on Regenerative Suspension Energy-Regeneration and Dynamic Performance
}

\author{
Ruochen Wang, Yanshu Ding, Qing Ye, Renkai Ding, and Jingang Qian \\ School of Automotive and Traffic Engineering, Jiangsu University, Zhenjiang 212013, China \\ Correspondence should be addressed to Ruochen Wang; wrc@ujs.edu.cn
}

Received 27 March 2017; Accepted 26 July 2017; Published 24 August 2017

Academic Editor: Michele Magno

Copyright (C) 2017 Ruochen Wang et al. This is an open access article distributed under the Creative Commons Attribution License, which permits unrestricted use, distribution, and reproduction in any medium, provided the original work is properly cited.

To study the effect of supercapacitor initial terminal voltage on the regenerative and semiactive suspension energy-regeneration and dynamic performance, firstly, the relationship between supercapacitor terminal voltage and linear motor electromagnetic damping force and that between supercapacitor terminal voltage and recycled energy by the supercapacitor in one single switching period were both analyzed. The result shows that the linear motor electromagnetic damping force is irrelevant to the supercapacitor terminal voltage, and the recycled energy by the supercapacitor reaches the maximum when initial terminal voltage of the supercapacitor equals output terminal voltage of the linear motor. Then, performances of system dynamics and energy-regeneration were studied as the supercapacitor initial terminal voltage varied in situations of B level and C level road. The result showed that recycled energy by the supercapacitor increased at first and then decreased while the dynamic performance had no obvious change. On the basis of previous study, a mode-switching control strategy of supercapacitor for the regenerative and semiactive suspension system was proposed, and the mode-switching rule was built. According to simulation and experiment results, the system energyregeneration efficiency can be increased by utilizing the control strategy without influencing suspension dynamic performance, which is highly valuable to practical engineering.

\section{Introduction}

Vibration impact of the vehicle body is converted into thermal energy and then dissipated by dampers, which greatly reduces utilization of energy generated by the engine [1-4]. Kinetic and potential energy of the vehicle body in vertical direction can be converted into electrical energy by power generation devices and then is utilized in the regenerative suspension system [5-9].

The control and energy storage circuit of the regenerative suspension system has been designed and researched by many scholars [10-15]. In researches of Tsinghua University and State University of New York, recycled energy in the electromagnetic and semiactive suspension was stored into the battery through a Buck-Boost switching converter, and the system activation force was adjusted by changing switching signal of the converter. Chen et al. have researched into the energy management system of the intelligent suspension [16-18]. A charge-discharge device was utilized in the research, which transferred the extra energy stored in the supercapacitor into a battery. However, effects of the charge-discharge device on energy-regeneration efficiency and dynamic performance were not analyzed.

A DC_DC converter can realize an effective control of the electromotor winding current, which has been applied to the regenerative suspension system to control the activation force, and serves as the path of energy output as well [1821]. The effect of a DC_DC converter on the suspension system dynamics and energy-regeneration efficiency, which had been often neglected, was analyzed in this paper. In addition, a mode-switching control strategy of supercapacitor for the regenerative and semiactive suspension system was proposed, which increased energy-regeneration efficiency on the premise of good suspension dynamic performance. 


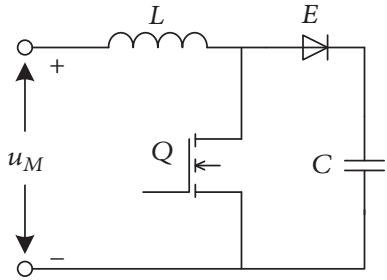

(a) The new Boost converter

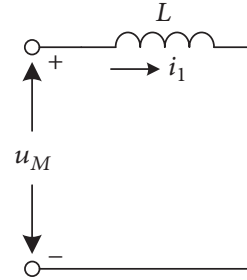

(b) Equivalent circuit when MOS pipeline $Q$ is conducted

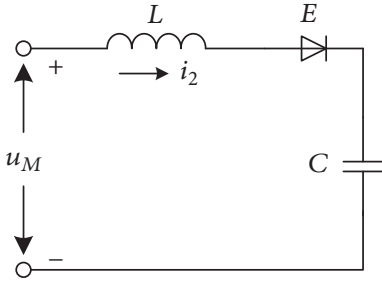

(c) Equivalent circuit when MOS pipeline $Q$ is cutoff

Figure 1

\section{Analysis of DC_DC Converter Operation Performance}

To realize semiactive control of the system and energyregeneration, the resistance of a traditional Boost circuit was replaced by a supercapacitor. The new topological structure is shown in Figure 1(a). $u_{M}$ is output terminal voltage of the linear motor which has been rectified by a rectifier.

Components of the circuit are assumed to be ideal; namely, conduction resistances of the diode and the MOS pipeline are both zero. The switching period is defined as $[-D T,(1-D) T] . T$ is period of the switching signal and $D$ is duty ratio of the switching period.

When $t \in[-D T, 0]$, as is shown in Figure 1(b), the MOS pipeline $Q$ is conducted, and $u_{M}$ is given by Kirchhoff Voltage Law (KVL):

$$
u_{M}=L \frac{d i_{1}}{d t} .
$$

From (1), $i_{1}$ can be calculated as

$$
i_{1}=\frac{u_{M}}{L}(t+D T)+I_{0} .
$$

$I_{0}$ is current of the inductor when $t=-D T$, and $i_{1}$ is current of the inductor when $t \in[-D T, 0]$.

When $t \in[0,(1-D) T]$, the MOS pipeline $Q$ is cutoff, and as is shown in Figure 1(c), the inductor $L$ and the power source $u_{M}$ both charge the supercapacitor. At this point

$$
\begin{aligned}
u_{M}+L \frac{d i_{2}}{d t} & =u_{0}+u_{C}, \\
i_{2} & =C \frac{d u_{C}}{d t} .
\end{aligned}
$$

$u_{0}$ is initial terminal voltage of the supercapacitor when $t=$ $0 . u_{c}$ is an increment of the supercapacitor terminal voltage during the time of $[0,(1-D) T]$, and $i_{2}$ is current of the inductor during $t \in[-D T, 0]$.

It can be calculated from (3) that

$$
u_{C}=k_{1} e^{t / \tau}+k_{2} e^{-t / \tau}+u_{M}-u_{0} .
$$

Further, from (3), $i_{2}$ is given as

$$
i_{2}=\sqrt{\frac{C}{L}}\left(k_{1} e^{t / \tau}-k_{2} e^{-t / \tau}\right) .
$$

In (5), $\tau=\sqrt{L C}, k_{1}$, and $k_{2}$ are undetermined coefficients.
When $t=0, u_{c}=0$, and $i_{1}=i_{2}$, thus

$$
\begin{aligned}
& k_{1}=\frac{u_{0}}{2}-\frac{u_{M}}{2}\left(1-\frac{D T}{\tau}\right)+\frac{I_{0}}{2} \sqrt{\frac{L}{C}}, \\
& k_{2}=\frac{u_{0}}{2}-\frac{u_{M}}{2}\left(1+\frac{D T}{\tau}\right)-\frac{I_{0}}{2} \sqrt{\frac{L}{C}} .
\end{aligned}
$$

Current in the circuit has a shape of triangular wave; thus mean value and virtual value of the current are equal. The mean value, as well as the virtual value, can be given as

$$
I=\frac{D T u_{M}}{2 L}+I_{0} .
$$

The output electromagnetic damping force of the linear motor is

$$
F=k_{i} \cdot I=\frac{k_{i} D T u_{M}}{2 L}+k_{i} I_{0} .
$$

In (8), $k_{i}$ is electromagnetic damping coefficient of the linear motor. It can been seen from (8) that output electromagnetic damping force of the linear motor, which is irrelevant to initial terminal voltage of the supercapacitor, is proportional to duty ratio of the switching signal. Further, it can be inferred that the initial terminal voltage of the supercapacitor does not influence the suspension dynamics.

The recycled energy $W$ in one period is

$$
W=\frac{1}{2} C\left[\left(u_{0}+u_{c}\right)^{2}-u_{0}^{2}\right]=\frac{1}{2} C\left(u_{c}^{2}+2 u_{c} u_{0}\right) .
$$

By derivation of $u_{0}$ in (9), it can be seen that $W$ reaches the maximum when

$$
u_{0}=\frac{u_{M}\left(e^{t / \tau}+e^{-t / \tau}\right)}{e^{t / \tau}+e^{-t / \tau}-2} .
$$

$W_{\max }$ is given as

$$
\begin{aligned}
& W_{\max }=\frac{u_{M}^{2}\left(e^{2 t / \tau}-e^{-2 t / \tau}\right)}{4\left(e^{t / \tau}+e^{-t / \tau}-2\right)^{2}}+\frac{u_{M}^{2}\left(e^{t / \tau}+e^{-t / \tau}\right)^{2}}{e^{t / \tau}+e^{-t / \tau}-2} \\
& -\frac{u_{M}\left(e^{t / \tau}+e^{-t / \tau}\right)}{e^{t / \tau}+e^{-t / \tau}-2}\left[\left(\lambda_{1}+\lambda_{2}\right)+\lambda_{1} e^{2 t / \tau}\right. \\
& \left.+\lambda_{2} e^{-2 t / \tau}\right]+\lambda_{1}^{2} e^{2 t / \tau}+\lambda_{2}^{2} e^{-2 t / \tau}+2 \lambda_{1} \lambda_{2} \\
& -2 u_{M}\left(\lambda_{1} e^{t / \tau}+\lambda_{2} e^{-t / \tau}\right)+u_{M}^{2} .
\end{aligned}
$$


TABLE 1: Simulation parameters.

\begin{tabular}{lcc}
\hline Parameter & Unit & $\begin{array}{c}\text { Parameter } \\
\text { value }\end{array}$ \\
\hline Sprung mass $m_{2}$ & $\mathrm{~kg}$ & 317.5 \\
Unsprung mass $m_{1}$ & $\mathrm{~kg}$ & 45.4 \\
Tire stiffness coefficient $k_{t}$ & $\mathrm{~N} \cdot \mathrm{m}^{-1}$ & 192000 \\
Spring stiffness coefficient $k$ & $\mathrm{~N} \cdot \mathrm{m}^{-1}$ & 22000 \\
Damping coefficient of the original & $\mathrm{N} \cdot \mathrm{s} \cdot \mathrm{m}^{-1}$ & 1500 \\
damper $c_{0}$ & $\mathrm{~V} \cdot \mathrm{s} \cdot \mathrm{m}^{-1}$ & 62.6 \\
Back EMF coefficient $k_{e}$ & $\mathrm{~N} \cdot \mathrm{A}^{-1}$ & 77.9 \\
Electromagnetic damping coefficient $k_{i}$ & & \\
\hline
\end{tabular}

In the above equation,

$$
\begin{aligned}
& \lambda_{1}=\frac{u_{M}}{2}\left(1-\frac{D T}{\tau}\right)-\frac{I_{0}}{2} \sqrt{\frac{L}{C}}, \\
& \lambda_{2}=\frac{u_{M}}{2}\left(1+\frac{D T}{\tau}\right)+\frac{I_{0}}{2} \sqrt{\frac{L}{C}} .
\end{aligned}
$$

The selected switching ratio $f$ of circuit design is $20 \mathrm{KHz}$ and $t \ll 1$. Thus, when $u_{0} \approx u_{m}$, the recycled energy by the supercapacitor reaches the maximum in one switching period. Therefore, the system energy-regeneration efficiency is highly dependent on the supercapacitor initial terminal voltage and the DC_DC converter characteristics (including inductance, switching frequency, and capacitance).

\section{Simulation Analysis}

To analyze the effect of the supercapacitor initial terminal voltage on the suspension dynamics and energyregeneration, a hybrid semiactive control strategy was applied to the vehicle single wheel model. Differential equations of the system dynamics are given as

$$
\begin{aligned}
& m_{2} \ddot{z}_{2}+k\left(z_{2}-z_{1}\right)+c_{0}\left(\dot{z}_{2}-\dot{z}_{1}\right)-F_{M}=0, \\
& m_{1} \ddot{z}_{1}+k\left(z_{1}-z_{2}\right)+k_{t}\left(z_{1}-q\right)+c_{0}\left(\dot{z}_{1}-\dot{z}_{2}\right)+F_{M} \\
& \quad=0, \\
& \dot{q}(t)=-0.111\left[v_{0} q(t)+40 \sqrt{G_{q}\left(n_{0}\right) v_{0}} w(t)\right] .
\end{aligned}
$$

In the above equation, $m_{2}$ is the sprung mass, $m_{1}$ is the unsprung mass, $q(t)$ is the road displacement input, $k$ is the spring stiffness, $k_{t}$ is the tire stiffness, $c_{0}$ is the damping coefficient of the traditional damper, $F_{M}$ is the electromagnetic damping force of the linear motor, $G_{q}\left(n_{0}\right)$ is the road roughness coefficient, $w(t)$ is white Gaussian noise with an average of zero, and $v_{0}$ is the vehicle speed.

The simulation situations were a speed of $30 / \mathrm{s}$ on the B level and the $\mathrm{C}$ level roads. Simulation parameters are listed in Table 1 [20].

In the simulation, the supercapacitor pack was composed by 12 supercapacitors $(100 \mathrm{~F}, 2.5 \mathrm{~V})$. Switching frequency was

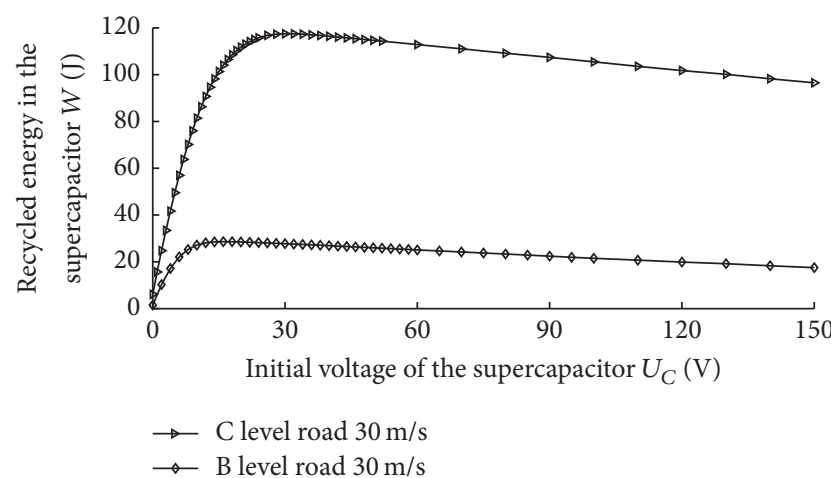

FIgURE 2: The relationship between recycled energy by the supercapacitor and the initial terminal voltage.

$20 \mathrm{KHz}$ and duty ratio was 50\%. Simulation results are shown in Figures 2-5.

According to Figure 2, recycled energy by the supercapacitor increased rapidly at first and then decreased slowly as the supercapacitor initial terminal voltage increased, while the suspension dynamic performance had no obvious change according to Figures 3-5. Therefore the effect of supercapacitor initial terminal voltage on suspension dynamics could be neglected.

\section{Research into the Mode-Switching Control Strategy of Supercapacitor}

A mode-switching control strategy of supercapacitor for the regenerative and semiactive suspension system was proposed based on the above simulation results. The control strategy can increase the energy-regeneration efficiency of the suspension system without influencing the suspension dynamics. Switching logic is shown in Figure 6.

When the supercapacitor terminal voltage is greater than the upper threshold, the charging capacitor turns into discharging mode and charges the vehicle battery, and when the supercapacitor terminal voltage is less than the lower threshold, the discharging capacitor turns into charging mode and recycles the electromotor vibration energy.

According to the above analysis, the effect of the supercapacitor terminal voltage on suspension dynamics can be neglected but has a great influence on energy-regeneration. For the simulation of B level road, the supercapacitor modeswitching range was $[10 \mathrm{~V}, 20 \mathrm{~V}]$, while for the simulation of $\mathrm{C}$ level road, the mode-switching range was $[15 \mathrm{~V}, 30 \mathrm{~V}]$.

After utilizing the mode-switching control strategy of the supercapacitor, simulation results of the system recycled energy $W$, the root-mean-square value of vehicle body acceleration $a_{w}$, the root-mean-square value of suspension dynamic travel $\mathrm{SWS}_{\mathrm{rms}}$, and the root-mean-square value of tire dynamic load $\mathrm{DTL}_{\mathrm{rms}}$ are shown in Table 2. (1) denotes the mean value of the parameter, and (2) denotes the increased percentage of the parameter after utilizing the mode-switching strategy.

As is shown in Table 2, the vehicle body acceleration and the tire dynamic load both had improvement, which were 


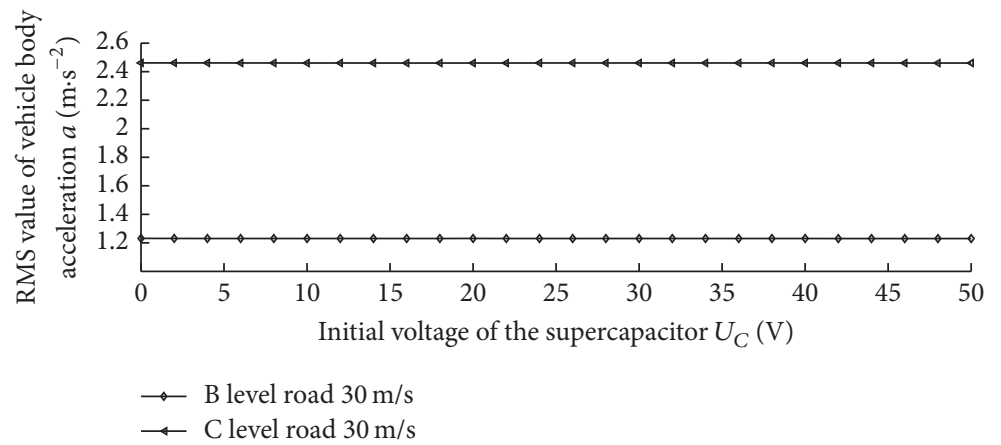

FIGURE 3: The relationship between vehicle body acceleration and supercapacitor initial terminal voltage.

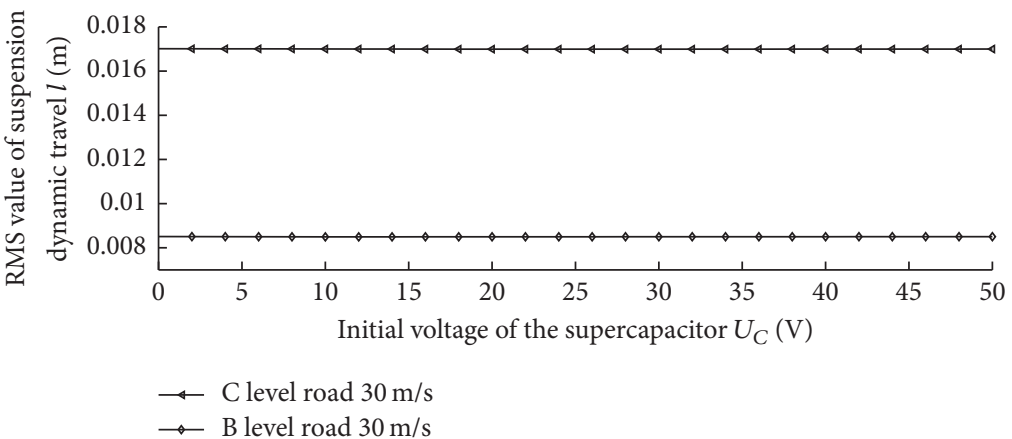

FIGURE 4: The relationship between suspension dynamic travel and supercapacitor initial terminal voltage.

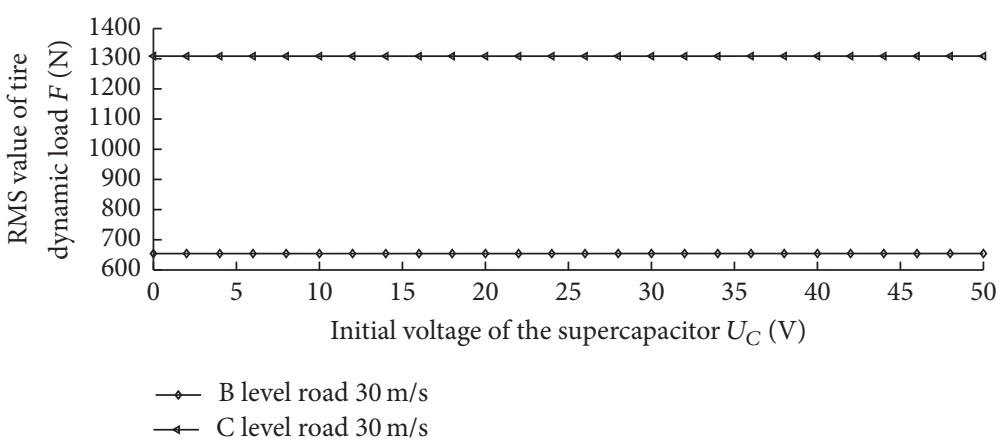

FIGURE 5: The relationship between tire dynamic load and supercapacitor initial terminal voltage.

not very obvious. The suspension dynamic travel got a little worse, which could be neglected. However, recycled energy by the supercapacitor greatly increased. Particularly in the simulation of $\mathrm{C}$ level road with a speed of $30 \mathrm{~m} / \mathrm{s}$, recycled energy had an increase by $17.8 \%$. Thus, the mode-switching control strategy has no effect on the dynamic performance of vehicle body while bringing an apparent optimization to the energy-regeneration efficiency of the regenerative and semiactive suspension system.

\section{Experiment Research}

The output terminal of the linear motor was connected by a rectifier to the DC Boost converter, which was used to build
TABLE 2: Simulation results with mode-switching of the supercapacitor.

\begin{tabular}{lccccc}
\hline & & $W / \mathrm{J}$ & $a_{w} / \mathrm{m} \cdot \mathrm{s}^{-2}$ & $\mathrm{SWS}_{\mathrm{rms}} / \mathrm{mm}$ & $\mathrm{DTL}_{\mathrm{rms}} / \mathrm{N}$ \\
\hline \multirow{2}{*}{$\mathrm{B}-30$} & $(1)$ & 28.24 & 1.2304 & 8.495 & 654.3 \\
& $(2)$ & $14 \%$ & $-0.02 \%$ & $0.1 \%$ & $-0.005 \%$ \\
$\mathrm{C}-30$ & $(1)$ & 112.1 & 2.4608 & 16.994 & 1308.6 \\
& $(2)$ & $17.8 \%$ & 0 & $0.04 \%$ & $-0.003 \%$ \\
\hline
\end{tabular}

the regenerative and semiactive suspension system. Then the whole equipment was installed to the hydraulic servo and vibration actuator platform with single channel to conduct 


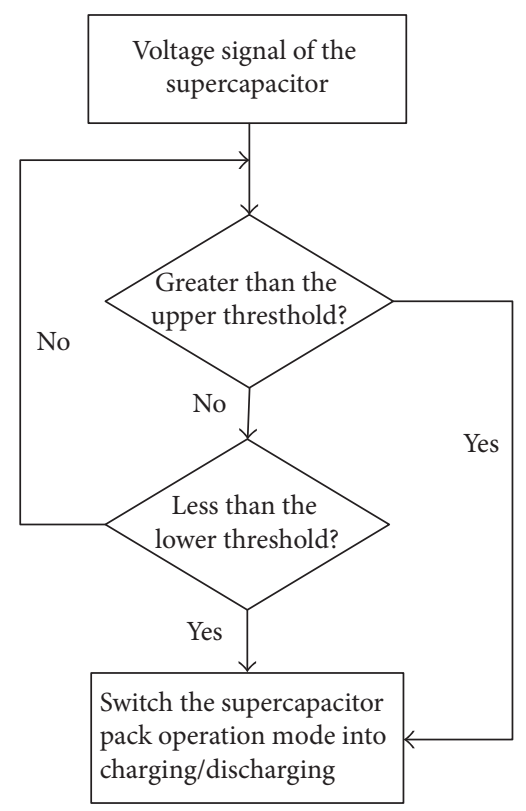

FIGURE 6: The switching logic of supercapacitor operation mode.

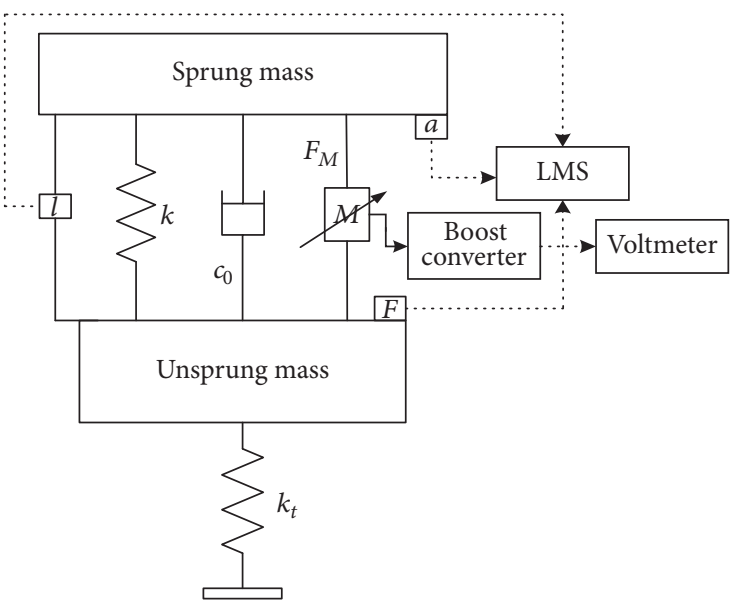

(a) Structure diagram of the suspension system

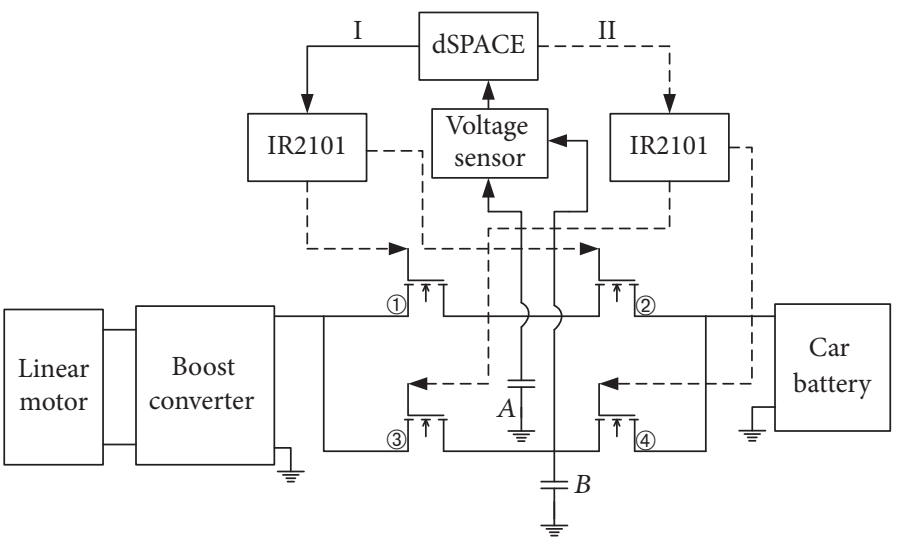

(b) Schematic diagram of the supercapacitor mode-switching

FIGURE 7: Experiment schematic diagram.

bench test. Finally, the experiment was conducted. Structure diagram of the suspension system is shown in Figure 7(a). The supercapacitor pack consisted of 12 capacitors $(2.5 \mathrm{~V} 100 \mathrm{~F})$ in series. The switching signal was frequency $20 \mathrm{KHz}$, duty ratio $50 \%$, low level voltage $0 \mathrm{~V}$, and high level voltage $5 \mathrm{~V}$. The inductance was $3.7 \mathrm{mH}$. As is shown in Figure 7(b), control unit of the mode-switching control strategy was dSPACE, into which the control strategy was loaded based on Matlab and ControlDesk together. Then, dSPACE output PWM wave to control the supercapacitor mode-switching circuit.

The effect of supercapacitor terminal voltage on dynamics and energy-regeneration of the regenerative and semiactive suspension was analyzed with increasing the initial terminal voltage gradually. Experimental situations were $30 \mathrm{~m} / \mathrm{s}$ on B level and $\mathrm{C}$ level roads. Experimental results are shown in Figures 8-11.

According to Figure 8, recycled energy by the supercapacitor increased at first and then decreased as the supercapacitor initial terminal voltage increased. In the experimental situation of $30 \mathrm{~m} / \mathrm{s}$ on B level road, recycled energy was much less than that in $\mathrm{C}$ level road situation, because output terminal voltage of the linear motor was much lower, making it very difficult for the supercapacitor to recycle energy.

According to Figures 9-11, the root-mean-square values of vehicle body acceleration, suspension dynamic travel, and tire dynamic load fluctuated randomly as the supercapacitor 


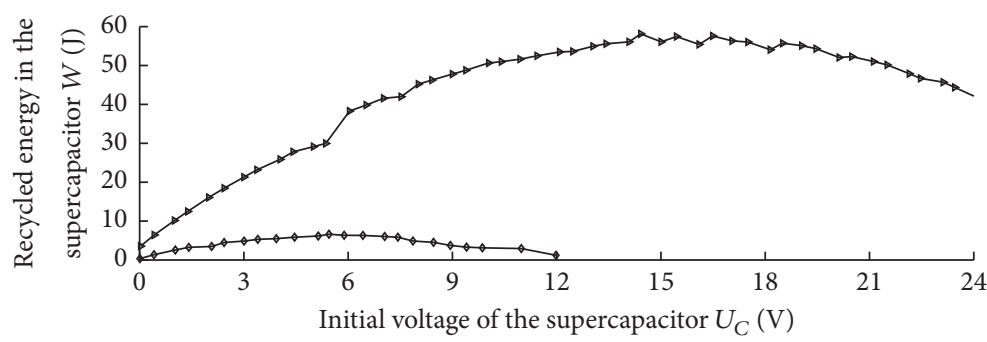

$\rightarrow \quad$ C level road $30 \mathrm{~m} / \mathrm{s}$

$\rightarrow$ B level road $30 \mathrm{~m} / \mathrm{s}$

FIgURE 8: The relationship between recycled energy by the supercapacitor and the initial terminal voltage.

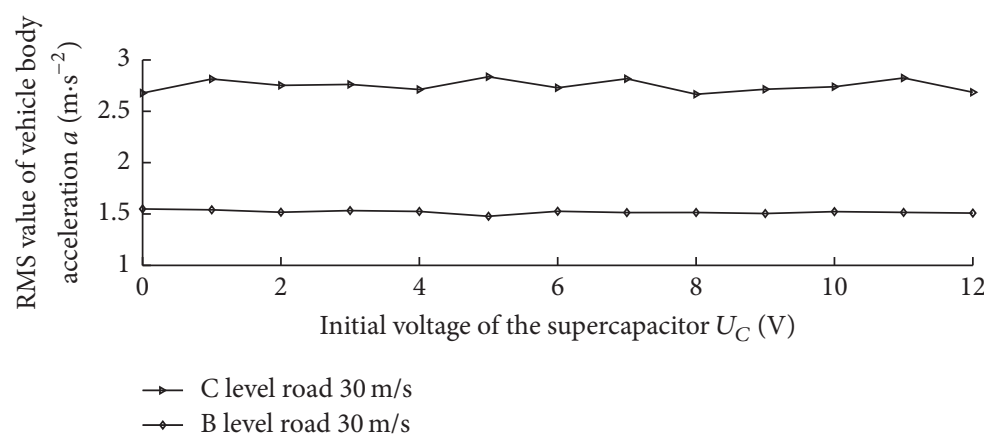

FIGURE 9: The relationship between vehicle body acceleration and supercapacitor initial terminal voltage.

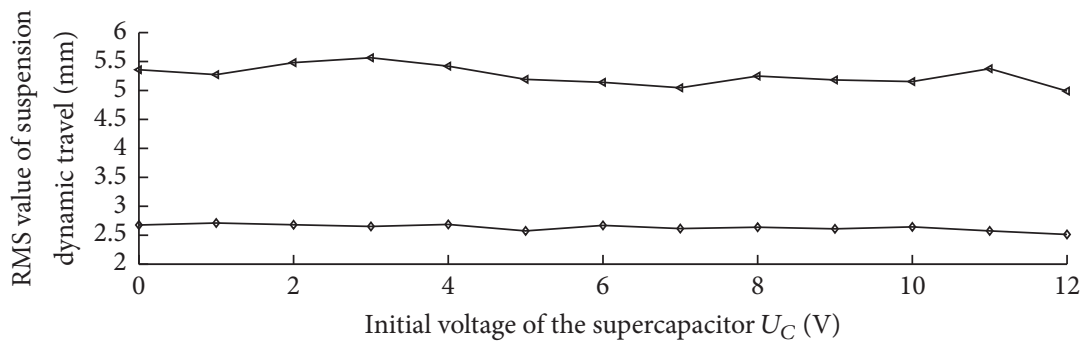

C level road $30 \mathrm{~m} / \mathrm{s}$

B level road $30 \mathrm{~m} / \mathrm{s}$

FIgURE 10: The relationship between suspension dynamic travel and supercapacitor initial terminal voltage.

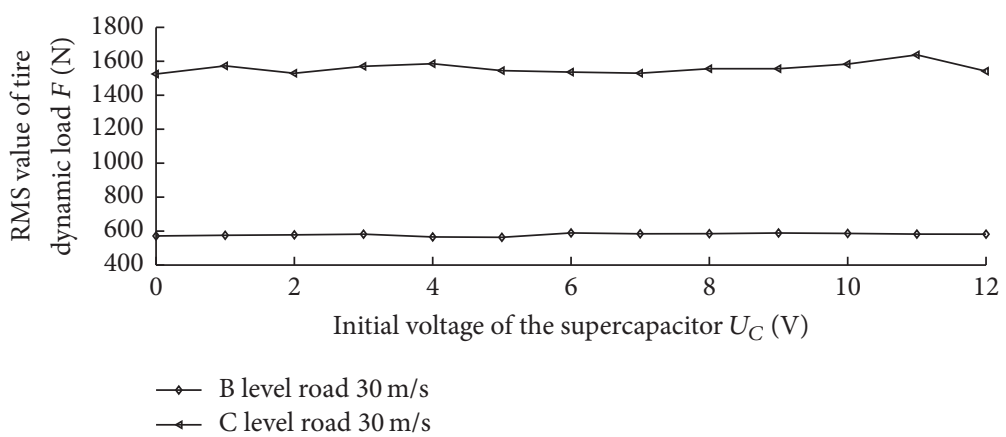

FIGURE 11: The relationship between tire dynamic load and supercapacitor initial terminal voltage. 
TABLE 3: Experiment results with mode-switching of the supercapacitor.

\begin{tabular}{lccccc}
\hline & & $W / \mathrm{J}$ & $a_{w} / \mathrm{m} \cdot \mathrm{s}^{-2}$ & $\mathrm{SWS}_{\mathrm{rms}} / \mathrm{mm}$ & $\mathrm{DTL}_{\mathrm{rms}} / \mathrm{N}$ \\
\hline \multirow{2}{*}{$\mathrm{B}-30$} & $(1)$ & 5.79 & 1.515 & 2.639 & 578.0 \\
& $(2)$ & $35.9 \%$ & $-0.26 \%$ & $0.19 \%$ & $-0.22 \%$ \\
$\mathrm{C}-30$ & $(1)$ & 53.60 & 2.751 & 5.166 & 1560.9 \\
& $(2)$ & $24.9 \%$ & $0.11 \%$ & $-1.86 \%$ & $0.1 \%$ \\
\hline
\end{tabular}

initial terminal voltage increased, but the fluctuations were small and showed no apparent rule. Instabilities of the test bench structure and sensors operation, as well as serious shakes and frictions of the displacement sensor expansion link, were major reasons of the fluctuations. The fluctuations on $\mathrm{C}$ level road were much larger than that on B level road, but the fluctuations on C level road were still relatively small.

The mode-switching circuit of the supercapacitor was applied to the regenerative and semiactive suspension system, and the influence mechanism of the supercapacitor modeswitching control strategy on system dynamics and regeneration performance was studied with experiments. As is shown in Figure 7(b), the control unit dSPACE output two opposite pulse signals (I and II) to two driver chips (IR2101), respectively. Then both driver chips output two opposite pulse signals to control the four switching tubes (1)-(4) and finally mode-switching of the supercapacitor was realized.

When the maximum and the minimum of the modeswitching voltage range were much closer to the corresponding supercapacitor terminal voltage at which recycled energy reached the maximum, the actually recycled energy would become larger. As for the actual circuit, frequent mode-switching of the supercapacitor will cause energy consumption of the circuit, which decreases the energyregeneration efficiency. With comprehensive consideration, the mode-switching ranges of the supercapacitor on $\mathrm{B}$ level road and $\mathrm{C}$ level road are $[3 \mathrm{~V}, 8 \mathrm{~V}]$ and $[11 \mathrm{~V}, 23 \mathrm{~V}]$, respectively. Experimental results are shown in Table 3. (1) denotes the mean value of the parameter, and (2) denotes the increased percentage of the parameter after utilizing the mode-switching strategy.

The experimental result with mode-switching control strategy of the supercapacitor was in accordance with the simulation result. Fluctuation amplitude of dynamic performance increased in experiment compared with that in simulation, but the increment is less than $2 \%$. And increment of energy-regeneration efficiency in experiment was always greater than that in simulation. Therefore, the effect of supercapacitor mode-switching control strategy on system dynamics can be neglected but greatly increases energyregeneration efficiency of the system, which is highly valuable to practical engineering.

\section{Conclusions}

(1) As initial terminal voltage of the supercapacitor increases, vehicle body acceleration, suspension dynamic travel, and tire dynamic load have no obvious change while recycled energy by the supercapacitor increases at first and then decreases.

(2) The proposed supercapacitor mode-switching control strategy for the regenerative and semiactive suspension system hardly influences the system dynamic performance but can greatly increases energy-regeneration efficiency of the system.

\section{Conflicts of Interest}

The authors declare that they have no conflicts of interest.

\section{References}

[1] X. Tang, T. Lin, and L. Zuo, "Design and optimization of a tubular linear electromagnetic vibration energy harvester," IEEE/ASME Transactions on Mechatronics, vol. 19, no. 2, pp. 615622, 2014.

[2] K. Efatpenah, J. H. Beno, and S. P. Nichols, "Energy requirements of a passive and an electromechanical active suspension system," Vehicle System Dynamics, vol. 34, no. 6, pp. 437-458, 2000.

[3] S. Kalpesh and R. Rajesh, "Zero-energy active suspension system for automobiles with adaptive sky-hook damping," Journal of Vibration and Acoustics, Transactions of the ASME, vol. 135, no. 1, 2013.

[4] "Where the energy goes: gasoline vehicles," http://www.fueleconomy.gov/FEG/atv.shtml.

[5] F. Yu and Y. Zhang, "Technology of regenerative vehicle active suspensions," Transactions of the Chinese Society of Agricultural Machinery, vol. 41, no. 1, pp. 1-6, 2010.

[6] Y. Okada, H. Harada, and K. Suzuki, "Active and regenerative control of an electron dynamic-type suspension," JSME International Journal, vol. 40, Series C, no. 2, pp. 272-278, 1997.

[7] G. R. Wendel and G. L. Stecklein, "A regenerative active suspension system," SAE Technical Papers, 1991.

[8] Y.-C. Zhang, F. Yu, Y.-H. Gu, and X.-C. Zheng, "Isolation and energy-regenerative performance experimental verification of automotive electrical suspension," Shanghai Jiaotong Daxue Xuebao/Journal of Shanghai Jiaotong University, vol. 42, no. 6, pp. 874-877, 2008.

[9] F. Yu, M. Cao, and X. C. Zheng, "Feasibility Research of the Regenerative and Active Suspension," Journal of Vibration and Shock, vol. 24, no. 4, pp. 27-30, 2005.

[10] Z. Li, L. Zuo, J. Kuang, and G. Luhrs, "Energy-harvesting shock absorber with a mechanical motion rectifier," Smart Materials and Structures, vol. 22, no. 2, Article ID 025008, 2013.

[11] Z. Li, L. Zuo, G. Luhrs, L. Lin, and Y.-X. Qin, "Electromagnetic energy-harvesting shock absorbers: design, modeling, and road tests," IEEE Transactions on Vehicular Technology, vol. 62, no. 3, pp. 1065-1074, 2013.

[12] R. Q. Huang, Y. D. Xu, and T. M. Xiang, "Design of ECU for Vehicle Active Suspension," Journal of Xihua University (Natural Science Edition), vol. 26, no. 5, article 49, pp. 20-21, 2007.

[13] Y. Okada and H. Harada, "Regenerative control of active vibration damper and suspension systems," in Proceedings of the 35th IEEE Conference on Decision and Control. Part 4 (of 4), pp. 4715-4720, December 1996.

[14] J. H. Beno, M. T. Worthington, and J. R. Mock, "Suspension trade studies for hybrid electric combat vehicles," SAE Technical Papers, 2005. 
[15] D. A. Weeks, J. H. Beno, A. M. Guenin, and D. A. Bresie, "Electromechanical active suspension demonstration for off-road vehicles," SAE Technical Papers, 2000.

[16] X. Chen, H. Luo, and Z.-X. Deng, "Design of an energyregenerative suspension control system using linear motor and energy recovery analysis," Zhendong yu Chongji/Journal of Vibration and Shock, vol. 31, no. 8, pp. 124-129, 2012.

[17] H. Luo, X. Chen, Z.-X. Deng, F. Lai, and Y. Ma, "Research on control system of linear motor actuator used in active suspension," Xitong Fangzhen Xuebao/Journal of System Simulation, vol. 24, no. 7, pp. 1537-1542, 2012.

[18] X. Chen, Research on energy recovery of intelligent suspension based on electromagnetic actuator, Chongqing University, Chongqing, 2011.

[19] S.-S. Kim and Y. Okada, "Variable resistance type energy regenerative damper using pulse width modulated step-up chopper," Journal of Vibration and Acoustics, Transactions of the ASME, vol. 124, no. 1, pp. 110-115, 2002.

[20] Y. Okada, S.-S. Kim, and K. Ozawa, "Energy regenerative and active control suspension," in Proceedings of the 2003 ASME Design Engineering Technical Conferences and Computers and Information in Engineering Conference, pp. 2135-2142, usa, September 2003.

[21] Y. H. Gu, F. Yu, Y. C. Zhang et al., "Controller design and experimental study of electrical energy- regenerative suspension," Automobile Technology, vol. 11, pp. 40-44, 2007. 


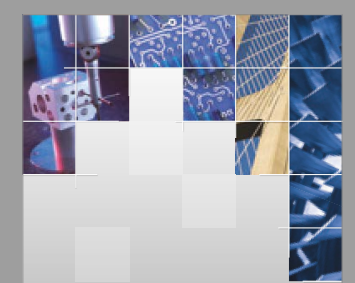

\section{Enfincering}
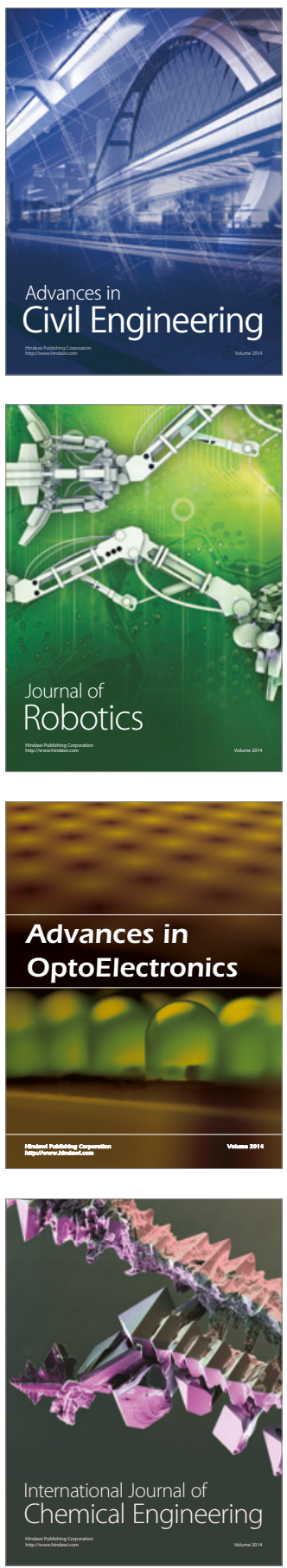

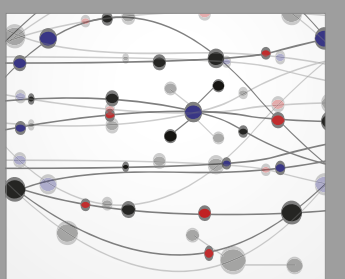

The Scientific World Journal

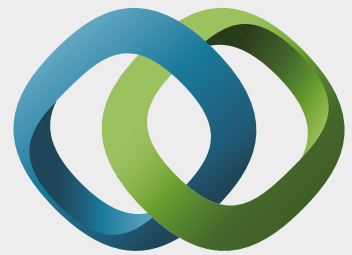

\section{Hindawi}

Submit your manuscripts at

https://www.hindawi.com
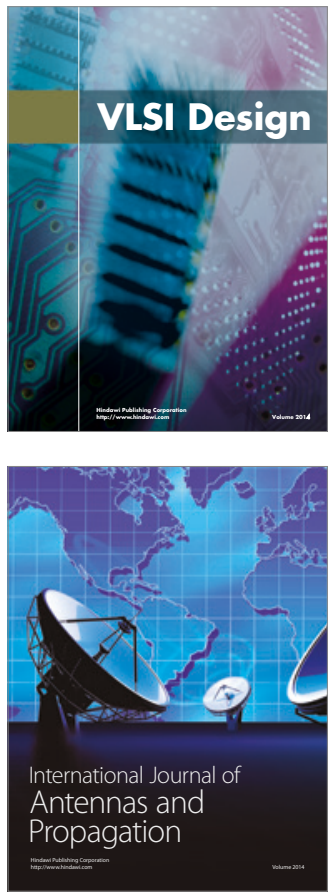

\section{Rotating}

Machinery
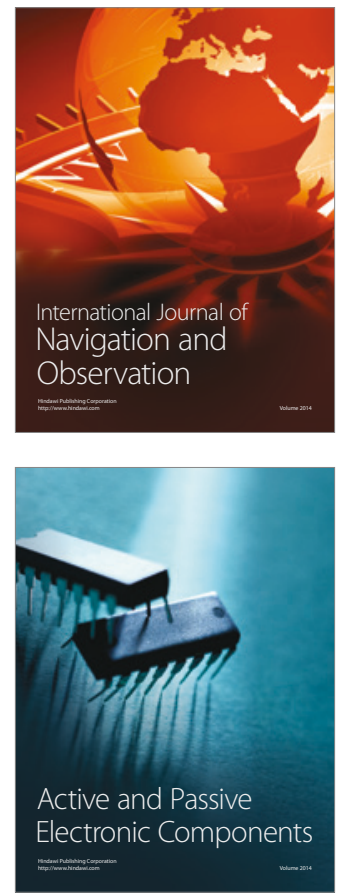
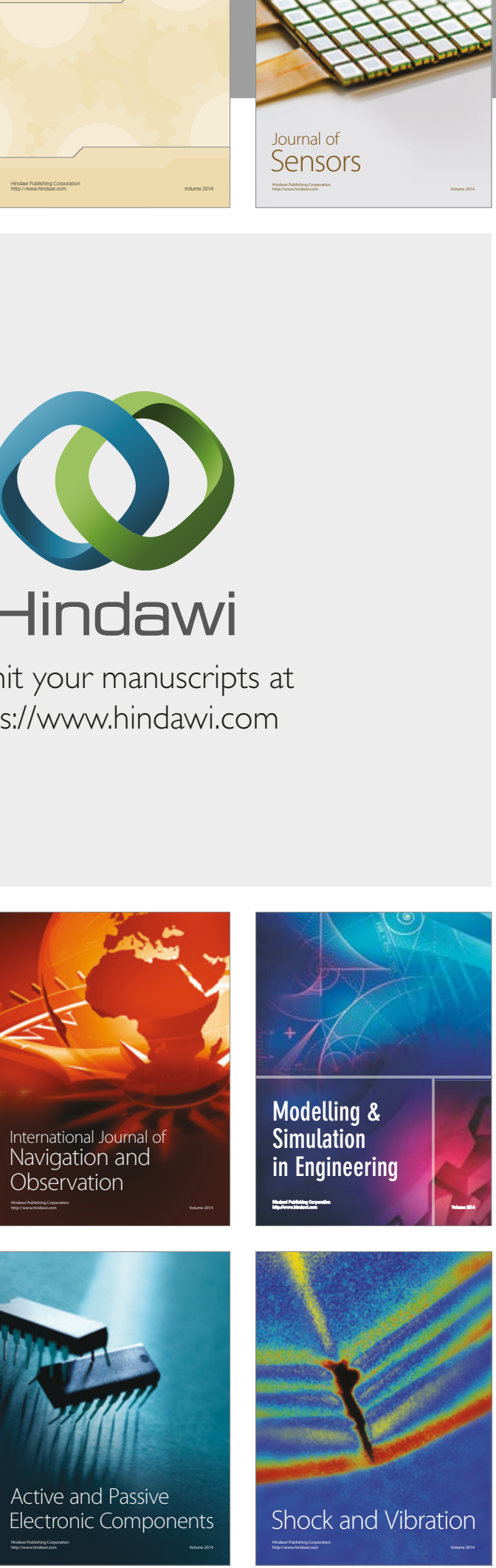
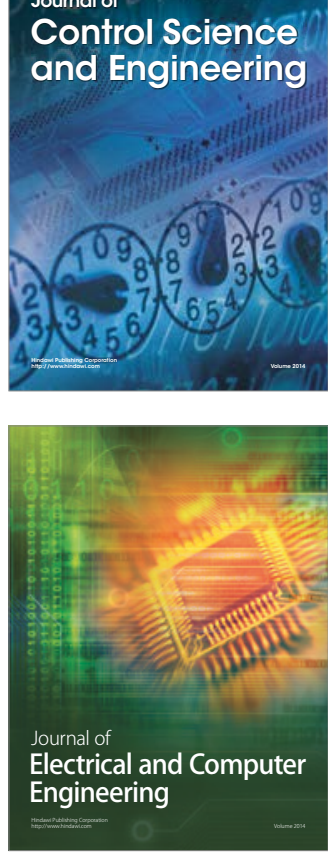

Distributed

Journal of

Control Science

and Engineering
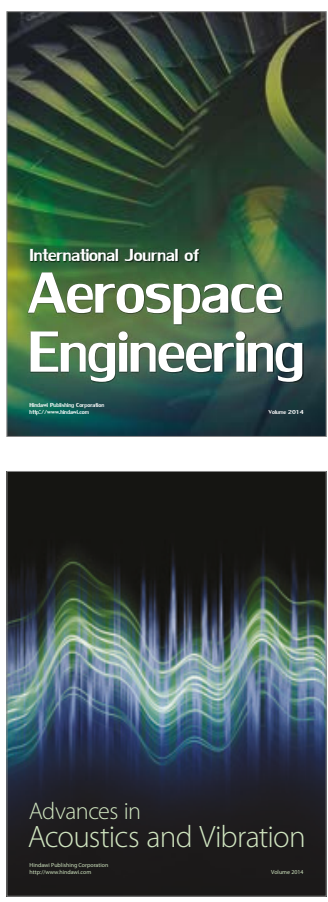

Sensor Networks 